\title{
Vowel but not consonant identity and the very informal English lexicon
}

\author{
Anne-Michelle Tessier ${ }^{1}$ and Michael Becker ${ }^{2}$ \\ ${ }^{1}$ Simon Fraser University and University of Michigan and ${ }^{2}$ Stony Brook University
}

\section{Introduction: morpho-phonological processes at the lexicon's edge}

One compelling argument that phonological processes and distributional restrictions are not just static memorized facts, but rather active influences on productive language use, are speakers' intuitions about novel word-building processes. Many studies have found that several rather niche morphological processes rely on prosodic structures, especially the phonological foot: first, McCarthy (1982) on expletive infixation; likewise McCarthy \& Prince (1998) on nicknames and truncation (see also Boyd-Bowman 1955, Kennedy \& Zamuner 2006, a.o.); Elfner \& Kimper (2008) on diddly-infixation; Yu (2003) on Homeric infixation; Viau (2006) on [rz]-infixation, and others since. A recurrent theme in these findings is that these word-building processes are not part of any formal or reified lexicons, but rather emerge organically within the speech community. As such, they can also demonstrate the influence of putative universal constraints which are active in other phonologies but are not otherwise observable in English. As one recent example: Moreton et al. (2017) find that faithfulness to nouns and head nouns makes sense of English speaker intuitions about the meanings of blends, despite a lack of an observable noun faithfulness effect elsewhere in the phonology of English.

In this paper, we go beyond the aforementioned prosodic restrictions on novel morphology, and discuss gradient segmental preferences. We use morphological compounding to probe English speakers' intuitions about the phonological goodness of long-distance vowel and consonant identity, or complete harmony. While compounding is a central mechanism for word-building in English, its phonology does not impose categorical vowel or consonant agreement patterns, even though such patterns are attested cross-linguistically. The compound type under investigation is a class of insult we refer to as shitgibbons, taking their name from the most prominent such insult which recently appeared in popular online media ( $(2)$. We report the results of three online surveys in which speakers rated novel shitgibbons, which did or did not instantiate long-distance harmonies (§3). With the ratings data established, we follow two lines of inquiry to consider their source: first, we compare shitgibbon harmony preferences with the frequency of segmental harmony in English compounds more generally, and conclude that the lexicon displays both vowel and consonant harmony ( $\$ 4)$; second, we attribute the lack of productive consonant harmony in shitgibbons to the attested cross-linguistic harmonies, which we implement as a locality bias in MaxEnt grammar (§5).

\section{The linguistic structure of shitgibbons}

2.1 General overview The class of shitgibbons is defined by prosodic and morphological properties. On the prosodic side, it must match a template of one heavy syllable bearing primary stress, followed by a trochee bearing secondary stress: $(' \sigma)(\sigma \sigma)$. The prosodic structure is optimal in (at least) four ways: first, each foot is at least bimoraic (since these English obscenities are minimally bimoraic), second, the second member of the compound is syllabically binary; third, the pair of feet join to make a binary higher-level structure; and fourth, the resulting structure is heavier on its right side (for a recent survey of end weight preferences, see Ryan submitted).

Its morphological components are a monosyllabic obscene word (the first syllable) combined with fairly

\footnotetext{
* For their thoughtful comments and constructive discussion, we thank John Alderete, Ashley Farris Trimble, Sara Mackenzie, and Henny Yeung. We also thank the audience at AMP 2017, especially Lev Blumenfeld, Cara Feldscher, and Yining Nie. For generously sharing their corpora, we thanks Mary Sepp, Andy Martin, and Lelia Glass and her collaborators. We reluctantly take responsibility for any remaining errors, if indeed there are any. This research was funded by SSHRC Insight Grant \#435-2015-0176 awarded to the first author.
}

(c) 2018 Anne-Michelle Tessier and Michael Becker

Proceedings of AMP 2017 
innocuous noun as trochee. The semantic contribution of the second word is somewhat murky to us the best examples seem to use nouns that are familiar, concrete, possibly whimsical, and/or humble (food products, household tools and animal names are especially good options.) The recent rise of the shitgibbon at least in North America was spurred by the following two social media posts, both responses to statements by Donald Trump:

(1) Tweet from @ metalollie, June 24, 2016: "Scotland voted to stay \& plan on a second referendum, you tiny fingered, Cheeto-faced, ferret wearing shitgibbon"

(2) Facebook post from Pennsylvania State Senator Daylin Leach, February 7, 2017: "Hey! I oppose civil asset forfeiture too. Why don't you come after me you fascist, loofa-faced shit-gibbon!!"

As discussed in online forums especially after the appearance of (1), shitgibbons are perhaps better known and more frequently coined in Scotland or elsewhere in the UK than in North America; see Zimmer (2017) for more as to origin stories.

2.2 Harmonic shitgibbons: research questions The aspect of shitgibbons we will focus on deals with segmental phonology: the initial intuition is that a shitgibbon makes a particularly satisfying insult because its two stressed vowel are identical (Jones, 2017). As the following non-exhaustive list suggest, this stressed vowel matching is observed in many naturally occurring shitgibbons:

(3) fucktrumpet, cuntmuffin, cockwaffle, shitgibbon, piss-biscuit...

Our first question is thus whether this vowel matching intuition is stable and robust. Are the segmental phonological preferences strong enough to have an observable effect, even in the presence of strong semantic pressures on lexical selection?

Notice that, unlike the stressed vowels in (3), the onset consonants of the stressed syllables in these wild shitgibbons do not match. Could consonant harmony nevertheless improve a shitgibbon's phonotactic goodness? We note that interactions between stressed onset consonants across morpheme boundaries are certainly not unheard of; in the realm of speech production errors, it is precisely this word position that is likely to undergo metathesis or anticipatory overwriting (Shattuck-Hufnagel, 1979). Our second question, then, is whether stressed onset consonant matching improves shitgibbon judgments as well.

While our main question was about the effect of vowel identity or consonant identity, we were also able to use the survey data to examine the role of partial similarity, e.g. the effect of vowel backness or consonant place of articulation.

\section{Experiment: speakers' judgment of novel shitgibbons}

To measure the effect of matching stressed vowels and the effect of matching initial consonants, we created novel shitgibbons, which we then asked native speakers of English to judge on a scale of 1-5 as to how "satisfying" and how "funny" they were. As we will see below, matching vowels significantly boosted the judgments, while matching consonants hardly had any effect at all.

This section focuses on the largest of three experiments we ran, with 75 native speakers. Two pilot experiments with 50 native speakers each are discussed in $\S 3.5$.

3.1 Participants Participants were recruited by word of mouth online. Before the experiment began, speakers were asked to sign a consent form and indicate that they are at least 19 years old. After completing the experiment, participants were asked to self-report demographic information and linguistic background. Data was retained from the speakers who self-reported to be monolingual speakers of North American English ages 19 or older with no linguistic training. This yielded data from 75 speakers; the rest of the data on the server was discarded.

The participants took 7 minutes on average to complete the experiment (median 4 minutes, range 2-54).

3.2 Materials Shitgibbons were constructed by combining 10 monosyllabic obscene nouns with 55 innocuous trochaic nouns; a few examples are shown in (4) below. The stressed vowels in all nouns were one of four $[\mathfrak{x}, \mathrm{I}, \Lambda, \mathrm{a}]$. The initial consonants in the obscenities were one of the six [p, f, d, s, $\left.\int, \mathrm{k}\right]$ or lack of initial 


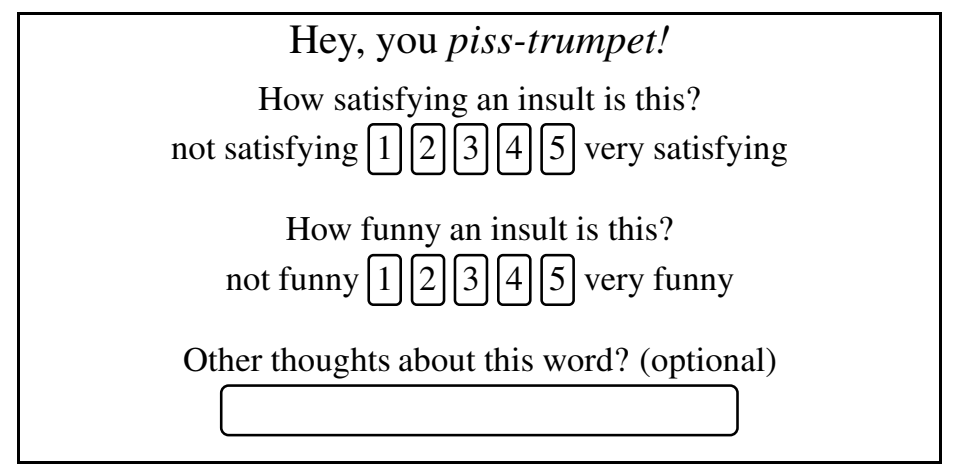

Figure 1: A sample item

consonant. The initial consonants of the innocuous nouns included the aforementioned options, and also [b, $\mathrm{m}, \mathrm{v}, \theta, \mathrm{t}, \mathrm{t}, \mathrm{I}, \mathrm{w}, \mathrm{h}]$. The nouns were chosen by the authors using their intuitions and dictionary searches, and the pilot experiments $(\S 3.5)$ were used to vet the innocuous nouns as making good second members of a shitgibbon, without being overly offensive when combined with the ten obscenities (Appendix A provides a full list). The selection ensured that for each obscenity, there were at least three innocuous nouns that share the obscenity's stressed vowel but not its initial consonant (or lack of consonant in the case of [æs] 'ass'), and at least three innocuous nouns that share the obscenity's initial consonant but not its stressed vowel.

(4) Sample of novel shitgibbons

\begin{tabular}{lll}
\hline No match & \#C match & V́ match \\
\hline fuck-whistle & fuck-frisbee & fuck-puffin \\
shit-dragon & shit-sharpie & shit-whistle \\
crap-puffin & crap-cobbler & crap-dragon \\
\hline
\end{tabular}

3.3 Procedure The experiment was delivered online, anonymously, using Experigen (Becker \& Levine, 2015). Using the given materials, the server randomly selected thirty shitgibbons for each participant, using each of the ten obscenities three times: one in which only the stressed vowels of the two nouns matched, one in which only the initial consonants matched, and one in which neither stressed vowels nor initial consonants matched.

In each trial, participants saw a screen like the one in Figure 1, and were asked to rate the shitgibbon in question on a Likert scale of 1 to 5 along two dimensions, "satisfying" and "funny", and to provide any optional comments they felt necessary. All shitgibbons were uniformly spelled with a hyphen between the obscenity and the following noun.

3.4 Results Participants judged shitgibbons with matching vowels as more satisfying (2.79 vs. 2.49) and funnier (2.80 vs. 2.46) than shitgibbons without matching vowels, while the effect of matching consonants was minuscule - less than a hundredth of a point on either of the 1-5 scales. In most trials, shitgibbons were judged as equally satisfying and funny (61\% of all trials), and the mean difference between the two ratings was negligible.

To estimate the reliability of the effects, and to predict the effect of the phonological properties of any future shitgibbons, the results were analyzed with a mixed-effects regression model in lme4 (Bates et al., 2015) in R (R Core Team, 2016). The effects of vowel and consonant matching were Helmert-coded as two predictors: no $V$ match vs. $V$ match, with a value of -.5 for no vowel match (regardless of consonants) and +1 for matching vowels, and no match vs. $C$ match, with a value of +1 for matching initial consonants, -1 for no match at all, and zero for matching vowels. These coding choices make the predictors centered and uncorrelated. The random effects consisted of a random intercept and a random slope for no $V$ match vs. $V$ match for each of participant, the obscene noun, and the innocuous noun. Two models, one for the 

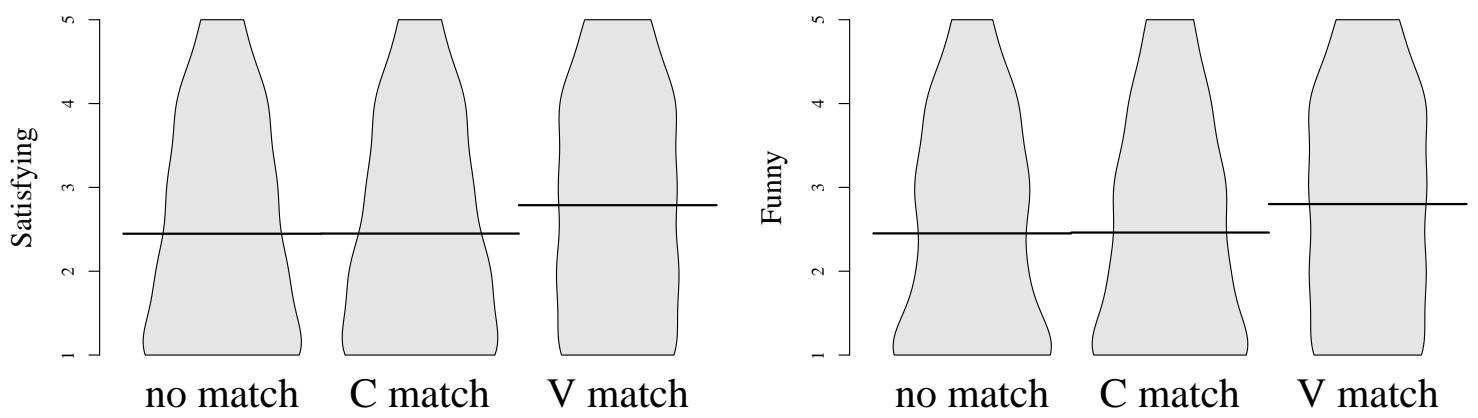

Figure 2: Overall "satisfying" and "funny" judgments of novel shitgibbons by 75 participants. Matching stressed vowels boost the judgments, matching initial consonants do not.

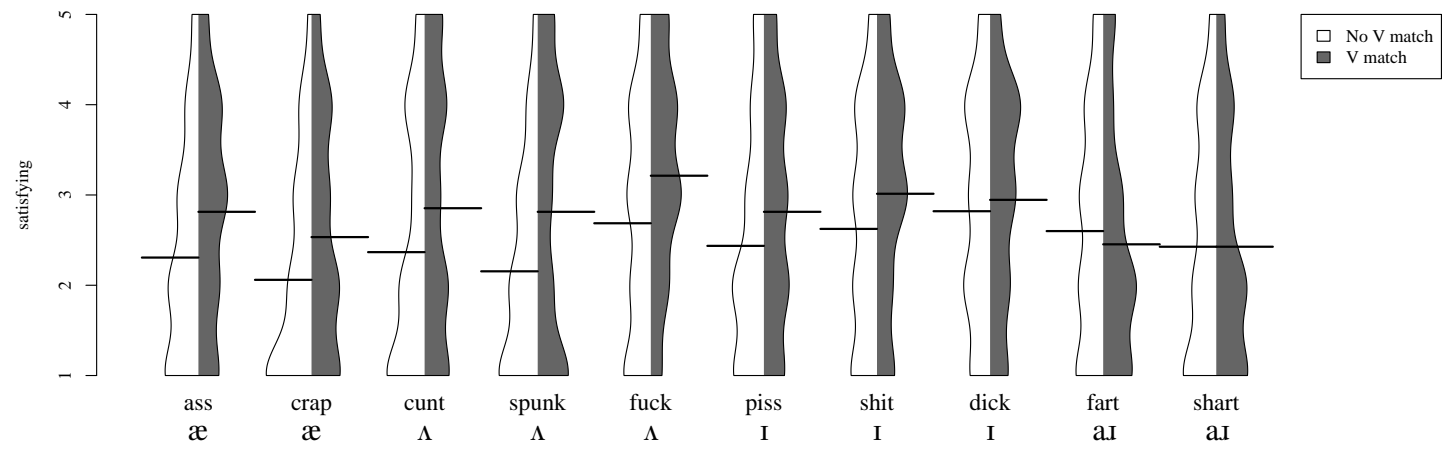

Figure 3: Results by obscenity; matching vowel effect strongest for [æ, $\Lambda$ ], smaller for [I], negligible for [aI].

dependent variable "satisfying" and one for the dependent variable "funny" are reported in Table 1, showing that matching vowels significantly boosted judgments, while the effect of matching consonants had almost no effect at all. The models are nearly identical in all respects, although the "satisfying" model accounts for more of the variance in the data ("satisfying": AIC 7040, BIC 6965, "funny": AIC 7180, BIC 7106).

A further question we wanted to assess is whether matching vowels boosted judgments as a part of a broader preference for matching vowel features. As discussed in $\S 5$, featural matching is typologically more common than total vowel identity. However, we see no evidence for featural matching in the data. Figure 4 shows the judgments of all vowel-vowel combinations, where total vowel identity is in dark gray. Pairs of non-identical vowels that match for backness (I with $æ, \Lambda$ with aI) are marked in light gray, and these are not consistently judged better than vowel pairs that do not match for backness (in white). This visual assessment was confirmed with a post-hoc model comparison, where a predictor for backness agreement was added to the "satisfying" model in Table 1; this predictor did not significantly improve the model $\left(\chi^{2}(1)=.39, p>.1\right)$. Similarly, the two phonetically long vowels [æ] and [aI] we compared to the two short vowels [I] and [ $\Lambda$; again no significant advantage was found $\left(\chi^{2}(1)=1.82, p>.1\right)$. We conclude that the evidence supports the role of total vowel matching, but not featural matching or partial matching.

As for the potential effect of partial consonant matching, a visual inspection did not reveal any noticeable trends. Given the tiny overall effect of the initial consonants, this is hardly surprising.

3.5 Additional experiments Two pilot experiments with fifty participants each were run in preparation for the current experiment. The same ten obscenities were used in all three experiment, and shitgibbons were presented using the same procedure as shown in Figure 1.

In the first pilot, each participant judged twenty shitgibbons, twice with each obscenity: either with a matching stressed vowel or with a non-matching stressed vowel. No matching initial consonants were 

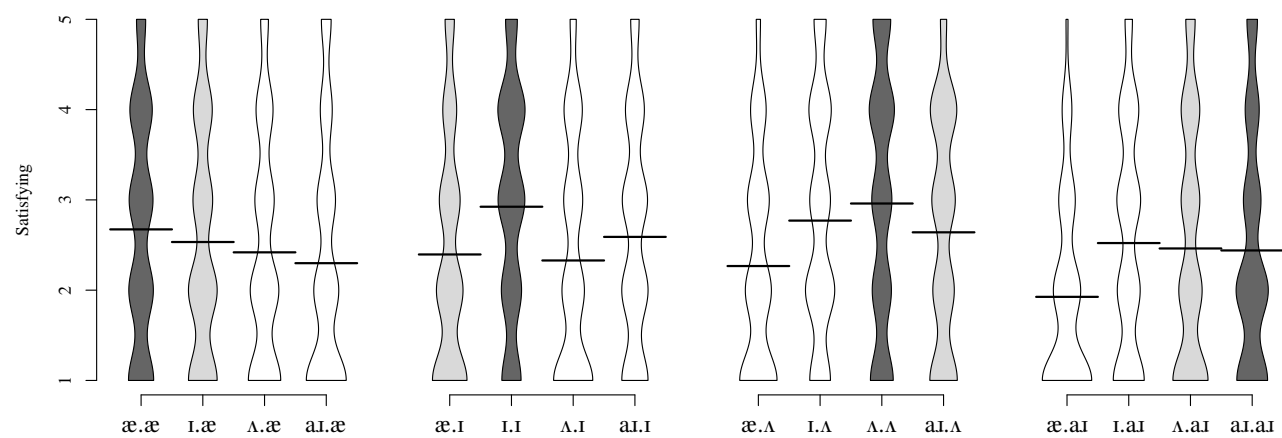

$\square$ Total V match

$\square$ Backness V match

$\square$ No V match

Figure 4: Judgments are consistently high for total vowel matching (dark gray), but matching vowel backness only (light gray) has no clear advantage over no matching at all (white).

\begin{tabular}{lrrr}
\hline "satisfying" & $\beta$ & $\mathrm{SE}(\beta)$ & $t$ \\
\hline (Intercept) & 2.55 & 0.11 & 24.10 \\
no match vs. C match & .02 & 0.03 & 0.84 \\
no V match vs. V match & .18 & 0.04 & 4.09 \\
\hline
\end{tabular}

\begin{tabular}{lrrr}
\hline "funny" & $\beta$ & $\mathrm{SE}(\beta)$ & $t$ \\
\hline (Intercept) & 2.58 & 0.11 & 24.11 \\
no match vs. C match & .03 & 0.03 & 0.93 \\
no V match vs. V match & .19 & 0.05 & 3.92 \\
\hline
\end{tabular}

Table 1: Mixed-effects regression models for "satisfying" and "funny"; vowel matching significantly boosts judgments.

used. Shitgibbons with matching vowels were judged as .24 points more satisfying and .24 points funnier than shitgibbons without matching vowels on the 1-5 scale. The effect was significant in two mixed-effects regression analyses (satisfying: $\beta=.24, t=2.41, p<.05$, funny: $\beta=.25, t=2.62, p<.01$ ).

In the second pilot, each participant judged twenty shitgibbons, twice with each obscenity: either with a matching initial consonant or with a non-matching initial consonant. No matching stressed vowel were used. Shitgibbons with matching initial consonants were judged as only .03 points more satisfying and .07 points less funny than shitgibbons without matching initial consonants on the 1-5 scale. The effect was not significant in two mixed-effects regression analyses (satisfying: $\beta=.11, t=.96, p>.1$, funny: $\beta=-.04$, $t=-.31, p>.1)$.

The results of the two pilot studies, then, are perfectly in line with the results of the main study, confirming that matching vowels boost judgments but matching consonants do not.

3.6 Discussion and interim conclusions The experimental results establish that matching stressed vowels make shitgibbons significantly more well-formed (satisfying and funny) relative to shitgibbons without identical stress vowels, whereas consonantal identity had a negligible effect on their wellformedness. Furthermore, partial vowel identity, such as sharing a backness feature or sharing length, has no appreciable effect on shitgibbon wellformedness.

Below, we explore two kinds of explanations for these effects: (1) shitgibbon wellformedness reflects more general wellformedness restrictions on English compounds, which we discuss in $\S 4$, or (2) shitgibbon wellformedness reflect universal preferences for matching phonological elements, as reflected in the currently known typology of phonological processes in a variety of unrelated languages, which we review in $\S 5$. Our conclusion will synthesize both explanations: English compounds generally prefer matching vowels and matching initial consonants, but universal phonological considerations block the effect of the consonants.

\section{Long-distance segmental restrictions on existing English compounds}

To examine the possibility that vowel but not consonant matching are more general properties of English compounds, not just shitgibbons, we compiled a corpus of English two-word compounds and studied their 
segmental matching tendencies.

Our corpus is based on the work of Sepp (2006), Martin (2007), and Levin et al. (to appear), who generously shared their corpora with us. Our findings are that matching stressed vowels and matching initial consonants are both present in the English lexicon more frequently than expected by chance, although the preference for matching vowels is stronger.

4.1 The existing corpora Sepp (2006) and Martin (2007) are both two-word compound corpora that were collected from larger English general-purpose corpora, with 3222 and 4758 compounds, respectively. Levin et al. (to appear) is a corpus of 1652 compounds of food/cooking terms, from which we extracted the 1137 two-word compounds. The three corpora were combined to a single list of 9117 compounds, and duplicates were removed, which reduced the corpus to 8411 compounds. To gain access to American English pronunciations, the words were looked up in the CMU Pronouncing Dictionary. Since some words were not found in the CMU dictionary, the untranscribed compounds were removed, leaving a final corpus of 8008 two-word compounds. Of these, 1168 compounds had the ' $\sigma+{ }^{\prime} \sigma \sigma$ prosodic profile of a shitgibbon, i.e. a monosyllabic initial member and a disyllabic second member with initial stress.

As for the morphological composition of these compounds, the Martin (2007) corpus consists entirely of noun-noun compounds. The Sepp (2006) corpus doesn't provide part of speech information, but visual inspection suggests that it consists entirely of noun-noun compounds as well. Of the 1137 two-word compounds in the Levin et al. (to appear) corpus, $76 \%$ were noun-noun compounds, $22 \%$ were adjectivenoun compounds, and the rest were participle-noun compounds. The resulting combined corpus, then, is about $90 \%$ noun-noun compounds.

4.2 Simulations and results In our corpus, main stressed vowels match in $9.7 \%$ of the compounds, while initial consonants match in 7.7\%; these are marked with arrows in Figure 5. To compare these observed ratios to what is expected by chance, 10,000 Monte-Carlo simulations were run, where in each simulation initial members of compounds are randomly paired with second members of compounds. This technique has the advantage of keeping segmental frequencies unchanged, e.g., keeping $[\varepsilon]$ more frequent than $[\mathrm{u}]$, and $[\mathrm{k}]$ more frequent than $[\mathrm{t}]$.

The simulations are summarized in Figure 5, where the upper panel shows that main stressed vowels match on average in $8.3 \%$ of all compounds, with a standard deviation of $.3 \%$, putting the observed value of $9.7 \%$ at 4.8 standard deviations above the expected mean, which is highly significant $(p<.001)$. The result for initial consonants is similar, if weaker: the average simulation has initial matching consonants in $7.0 \%$ of all compounds, with a standard deviation of .3\%, putting the observed value of $7.7 \%$ at 2.6 standard deviations above the expected mean, which is significant $(p<.01)$.

If we limit ourselves to the 1168 compounds with a shitgibbon prosodic profile, i.e. ' $\sigma+{ }^{\prime} \sigma \sigma$, the results are similar. In this subset, main vowel matching is observed in $11 \%$ of the compounds, while a Monte-Carlo simulation provides an expected average of $8.5 \%$ with a standard deviation of $.8 \%$, making vowel matching 3.3 standard deviations above the expected mean, which is highly significant $(p<.005)$. For consonants, the effect is quite a bit weaker, with an observed average of $8.1 \%$, expected average of $6.9 \%$ with standard deviation of .7\%, making initial consonant matching only 1.73 standard deviations above the expected mean, which is not significant $(p>.05)$. It is not surprising, of course, that the statistical tendencies are weaker in the much smaller corpus.

To summarize, our simulations show that main stressed vowel matching occurs in English compounds highly significantly more often than expected, both in the corpus as a whole and in the shitgibbon-like subset. Initial consonants match more often than expected by chance, but not as often as vowels. The overrepresentation of initial consonant matching is significant in the corpus as a whole, but not in the shitgibbon-like subset.

\section{Analyzing vowel and consonant harmony, matching and preferences}

Many natural language phonologies impose vowel and consonant harmonies among non-adjacent segments (e.g. Rose \& Walker 2011). In a rather smaller subset of harmonic patterns, total harmony is imposed on the participating segments, as we observed in the stressed vowels of English shitgibbons. 


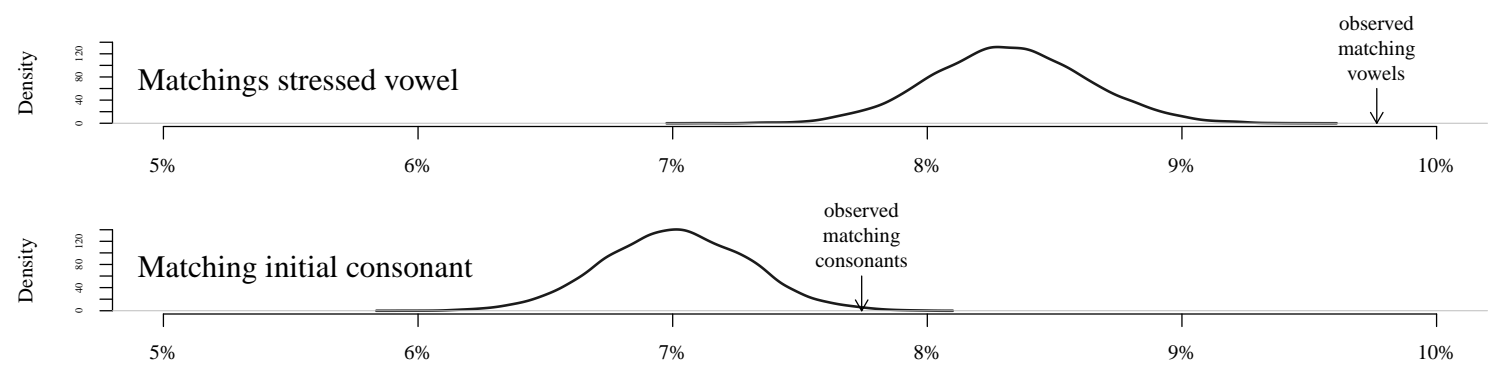

Figure 5: Monte-Carlo simulations of English compounds: matching vowels and matching consonants are observed significantly more often than expected by chance.

5.1 Comparisons with natural language phonologies Vowel identity is required in Kera (Chadic), which Pearce (2003) describes as requiring total identity among a root's vowels within the Prosodic Word (i.e. excluding a final light syllable). The examples in (5) show that with the exception of a final CV syllables, all other syllables within a root have identical vowels.

(5) Kera (Pearce, 2003): total vowel identity in the root

\begin{tabular}{llll}
\hline (fili)(liw) & 'hole in gourd' & $($ kuy)(kuruy) & 'leather bag' \\
(kef)(ter) & 'book' & $($ ko:)(mom) & 'rat' \\
(dibi)(bir) & 'lizard' & (ka:)(saw) & 'millet' \\
(gidi)ri & 'type/race' & (gidi)wa & 'stick' \\
*(gidi)(rig) & & $*$ (gidi)(wam) & \\
\hline
\end{tabular}

This pattern is quite comparable to the domain of shitgibbon vowel identity: in our experimental items we saw well-formedness improved by identity between two syllable-adjacent stressed vowels of the compound, to the exclusion to the final unstressed vowel. Thus whatever tier-based or other analysis is adopted to handle Kera-like harmonies should transfer well to our novel compound data.

With respect to consonants, there are also several non-local examples of total consonant identity in the literature. One well-known type of case is illustrated in (6) below from Bolivian Aymara (MacEachern, 1999; Gallagher, 2010), targeting the natural class of ejective (plosives and affricates). Roots can usually contain no more than one ejective (6a-b), but two ejectives are permitted only when the consonants are otherwise identical (6c). This can be therefore analyzed with a constraint that enforces total featural harmony among the natural class of stops in the root (for further arguments see Gallagher 2013, also Berent et al. 2012). Notice that sonorants may be skipped, e.g. the $[K]$ in $\left[\mathrm{k}^{\prime} \mathrm{a} \Lambda \mathrm{k}^{\prime} \mathrm{u}\right]$ neither prevents nor undergoes harmony: in Aymara, only stops may be ejectives, so sonorants and fricatives are transparent to the pattern.

(6) Aymara (MacEachern, 1999; Gallagher, 2010, 2013): Total matching of ejectives

\begin{tabular}{llll}
\hline \multicolumn{2}{l}{ a. one ejective } & b. two ejectives & \multicolumn{2}{l}{ c. two identical ejectives } \\
\hline p'eqe 'head' & *p'eq'e & p'ap'i & type of fish \\
t'aku 'calm' & *t'ak'u & t'ant'a & 'bread' \\
t'aka 'bone' & *t'ak'a & t'at'a & 'to soak' \\
k'apa 'cartilage' & *k'ap'a & k'aरk'u 'acidic' \\
q'olti 'drink' & *q'olt'i & q'oq'e & 'to catch fire' \\
\hline
\end{tabular}

Recent experimental findings from Linzen \& Gallagher (2017) also suggest that total consonantal identity of the Aymara type are very quickly learned in an artificial language learning context.

Do these attested examples differ in kind from the consonant identity pattern we did not observe in shitgibbons? We believe so, with respect to the domain over which they are enforced. 
A rich range of representations, constraints and mechanisms have been proposed for capturing the domains of long-distance harmonies, so that participating segments can interact over all and only the correct distances. One persistent approach to non-local harmony has been to assign separate vocalic and consonantal tiers (McCarthy 1979; Heinz 2010; a.o). Using such tiers, McMullin (2016) most recently argues that consonant harmonies can hold within two domains: either strictly transvocalic or unbounded, applying to all relevant segments on a tier. The Bolivian Aymara case in (6) is an example of unbounded harmony: while the languages roots are short and phonotactics are restrictive, the forms [t' ant'a] 'bread' and [k'a $\mathrm{k}$ ' $u$ ] 'acidic' demonstrate that any two ejectives separated by intervening segments must otherwise be identical to survive. In contrast, a clearly local consonant harmony is found in Koyra (7), which does not require full identity but only agreement for the feature [ \pm anterior]. Examples in (7a) show how a suffix consonant alternates to match the anteriority of a sibilant separated only by a vowel; examples in (7b) show that this harmony is not imposed when the two sibilants are more distant, interrupted by further syllables and consonants.

\begin{tabular}{clll}
\multicolumn{3}{c}{ Transvocalic sibilant harmony in Koyra (Koorete; Hayward } \\
\hline a. & /tim-d-os:o/ & tindos:o & 'he got wet' \\
& /patf-d-os:o/ & patf:of:o & 'it became less' \\
& /gi:3-d-os:o/ & gi:z:of:o & 'it suppurated' \\
b. & / Jod-d-os:o/ & fod:os:o & 'he uprooted' \\
& /Patf-ut-d-os:o/ & Patfut:os:o & 'he (polite) reaped' \\
\hline
\end{tabular}

In the case of our shitgibbons, the consonants under comparison are not separated merely by a vowel, but neither is harmony unbounded. Since all of our monosyllabic obscenities have coda consonants, the onset consonants should not be able to harmonize on either side; that is, the medial [k] in fuck-farmer or the [p] in crap-cobbler should block transvocalic harmony. But neither can harmony be unbounded, as that would require all consonants to be identical in the compound. The onset consonants of our monosyllabic obscenities are all obstruents [p, d, k, $\left.\int, \mathrm{f}\right]$, as are all of their codas, so even if the total identity restriction held only of obstruents, these medial codas would block harmony. It is therefore in line with natural language typology (at least as depicted by McMullin and others) that English speakers did not prefer total identity among the two roots' initial consonants.

5.2 The necessary components of a shitgibbon analysis We have shown that English compounds display vowel matching and consonant matching more often than expected by chance, and that English speakers preferred vowel but not consonant matching within our study of novel compound obscenities. We proposed that speakers' phonological judgments of this sublexicon are constrained by the same mechanisms that constrain natural language typology, which does not allow non-adjacent consonants to match without also matching all intervening consonants.

It is of course true that word-initial consonants do interact in speech errors (e.g. Goldrick 2002), especially those in stressed syllables, and across many intervening and unaffected segments. One hypothesis is that word-initial consonants may interact in speech planning and perhaps other very time-sensitive processing, but that longer-term generalizations over stable lexical items do not allow initial consonants to interact. We hope that future findings will shed further light on the cognitive mechanisms that regulate long-distance interactions between consonants.

Since the observed preference for matching vowels is gradient, both generally in English compounds and in the shitgibbon sublexicon, the proposed grammatical mechanism to capture this preference will have to be gradient or probabilistic as well; we adopt the Maximum Entropy framework for these reasons (Goldwater \& Johnson, 2003; Smolensky \& Legendre, 2006). While we model shitgibbons here, future work may show that vowel matching is preferred in all types of English compounds; we leave open the exact lexical scope of the proposed mechanism.

In this approach, the existing compounds in the English lexicon are a source for learning both vowel matching and consonant matching. The proposal does not explain why English compounds more generally display these preference for matching vowels and consonants, although perhaps grammatical pressures have amplified accidental lexical fluctuations over time (see e.g. Wedel 2007). To train the Maximum Entropy model, we used two markedness constraints, AGREE-V and AGREE-C, which penalize compounds that fail to agree in main stressed vowels and word-initial consonants respectively, as shown in (8). The model is trained 
on $\mathrm{O} / \mathrm{E}$ (observed/expected) ratios, where the observed numbers are the number of compounds in our corpus with the given properties (say, matching of neither consonants nor vowels) divided by the average number of such compounds in our simulations from $\S 4.2$. The $\mathrm{O} / \mathrm{E}$ ratios for vowel matching and consonant matching are high enough to give weight to both AGREE-V and AGREE-C. As expected, the weight of AGREE-V is higher, reflecting the greater overrepresentation of vowel matching. The training data contains $\mathrm{O} / \mathrm{E}$ ratios for compounds that match both vowels and consonants, since these exist in the corpus and in the simulations. The probability of such compounds is not predicted, however, since there were none in our survey data.

(8) Unbiased model: Consonant matching is predicted to improve wellformedness.

\begin{tabular}{|l|c|c|c|c|}
\hline & $\mathrm{O} / \mathrm{E}$ & $\begin{array}{c}\text { AGREE-V } \\
w=.26\end{array}$ & $\begin{array}{c}\text { AGREE-C } \\
w=.19\end{array}$ & prediction \\
\hline crap-puffin & .98 & $*$ & $*$ & .29 \\
\hline crap-cobbler & 1.07 & $*$ & & .34 \\
\hline crap-dragon & 1.15 & & $*$ & .37 \\
\hline V \& C match & 1.50 & & & - \\
\hline
\end{tabular}

The model in (8) predicts, incorrectly, that the wellformedness of consonant matching would be intermediate between no matching and vowel matching. Both constraints start with a weight of zero, but training the model on the given $\mathrm{O} / \mathrm{E}$ ratios allows both constraints to gain weight. To generate the preferences observed in $\S 3$, we suppress the constraint AGREE-C using a Bayesian prior that limits its ability to depart from zero $(\sigma=.001)$. The biased model, in (9), keeps the weight of AGREE-C close to zero, and so the predicted wellformedness of shitgibbons is sensitive only to vowel matching.

(9) Biased model: Consonant matching is not predicted to improve wellformedness.

\begin{tabular}{|l|c|c|c|c|}
\hline & $\mathrm{O} / \mathrm{E}$ & $\begin{array}{c}\text { AGREE-V } \\
w=.26\end{array}$ & $\begin{array}{c}\text { AGREE-C } \\
w=.01\end{array}$ & prediction \\
\hline crap-puffin & .98 & $*$ & $*$ & .30 \\
\hline crap-cobbler & 1.07 & $*$ & & .30 \\
\hline crap-dragon & 1.15 & & $*$ & .39 \\
\hline V \& C match & 1.50 & & & - \\
\hline
\end{tabular}

Were we to make predictions about compounds that match both vowels and consonants, the biased model would make nearly identical predictions for them and for matching of vowels only. Testing the validity of this prediction is left for future work; it is possible that a compound such as cock-cobbler might actually be judged worse than crap-cobbler, requiring some additional explanation. One shortcoming of the model in (9) is that it gives equal importance to the four types of compounds in the training data, since O/E ratios do not take the absolute values into account. Since compounds that match both vowels and consonants are rare in the data, speakers might rely on them less than our model does.

To summarize, the analysis sketched in (9) predicts that shitgibbons are more wellformed when they have matching stressed vowels, while the effect of matching consonants remains negligible. For concreteness, the analysis is implemented as a Maximum Entropy model (which allows it to learn trends in the lexicon and generalize them gradiently and productively to novel compounds), and includes a Bayesian prior that suppresses the role of AGREE-C. In fact, the analysis would be numerically unchanged in AGREE-C were to be removed completely. Including AGREE-C, however, opens that possibility that a sufficiently strong source of data would overcome this constraint. Furthermore, it opens the possibility that AGREE-C would be suppressed only contextually, allowing consonant matching to be preferred in some other linguistic context (say, in the presence of a certain affix).

\section{Conclusions}

This paper examined a newly prominent class of English compounds, dubbed shitgibbons, composed of a monosyllabic obscenity and a disyllabic innocuous noun. We have shown that when given novel shitgibbons, English speakers judge them as more "satisfying" and "funny" when the two stressed vowels are identical (e.g. crap-dragon is funnier than crap-puffin), but matching word-initial consonants do not boost judgements (e.g. crap-cobbler is not funnier than crap-puffin). 
We collected a corpus of English compounds by combining corpora from Sepp (2006), Martin (2007), and Levin et al. (to appear). Using Monte-Carlo simulations, we showed that both primary-stressed vowels and word-initial consonants match more often than expected by chance, although vowel matching is more strongly overrepresented. We thus observe a discrepancy between English compounds more generally (which prefer both vowel and consonant matching) and shitgibbons (which prefer vowel matching only). We connected this discrepancy to an asymmetry in the typology of vowel and consonant harmonies crosslinguistically: vowel identity in adjacent syllables may be required, skipping any intermediate consonants, while consonant identity cannot be established while skipping any intermediate consonant. Thus, the identical [f] sounds in e.g. fuck-frisbee do not improve the wellformedness of the compound due to the intervening [k] sound between the two [f]'s.

We implemented this analysis using a gradient Maximum Entropy model that is trained on the compound lexicon, with constraints that favor both vowel and consonant identity. Unbiased, this model learns the preference for both vowel and consonant matching, and thus predicts that consonant matching would boost wellformedness to a level that's intermediate between no matching and vowel matching. To more closely predict the actual results of our web survey, we added a typologically-supported prior to the model that limited the consonant matching effect; this biased model only learns the effect of vowel matching, and its predictions are in line with the survey results.

The current results expand the understanding of productively playful morphology in English. Studies such as McCarthy (1982); Yu (2003); Elfner \& Kimper (2008) and others focus on prosodic optimization. Shitgibbons conform to strict prosodic requirements that optimize their binarity and weight, but in addition they also show a tendency towards segmental optimization, i.e. they are more wellformed when their stressed vowels are identical.

\section{A Experimental results by item}

Items are listed with the number of times participants judged them, their average rating as "funny" and their average rating as "satisfying".

Matching vowels

\begin{tabular}{lrll}
\hline compound & $n$ & fun. & sat. \\
\hline ass-badger & 15 & 4.07 & 4.13 \\
ass-bracket & 10 & 2.50 & 2.70 \\
ass-camel & 5 & 2.00 & 2.20 \\
ass-fastner & 6 & 2.00 & 2.00 \\
ass-panda & 5 & 3.20 & 2.60 \\
ass-phantom & 4 & 2.75 & 3.00 \\
ass-rabbit & 5 & 3.20 & 3.00 \\
ass-shadow & 6 & 1.83 & 1.67 \\
ass-shamrock & 2 & 3.50 & 3.00 \\
ass-spaniel & 3 & 3.00 & 3.00 \\
ass-taxi & 14 & 2.86 & 2.43 \\
crap-antler & 9 & 2.22 & 2.11 \\
crap-apple & 9 & 2.67 & 2.22 \\
crap-badger & 8 & 2.25 & 2.75 \\
crap-bracket & 7 & 1.86 & 2.43 \\
crap-dragon & 3 & 2.67 & 4.00 \\
crap-fastner & 8 & 1.75 & 1.50 \\
crap-panda & 5 & 2.80 & 3.00 \\
crap-phantom & 6 & 2.33 & 1.67 \\
crap-rabbit & 8 & 3.38 & 2.88 \\
crap-shadow & 2 & 2.00 & 2.00 \\
crap-shamrock & 1 & 5.00 & 5.00 \\
crap-spaniel & 2 & 2.50 & 2.50 \\
crap-taxi & 7 & 3.57 & 3.71 \\
cunt-bucket & 10 & 2.70 & 3.20 \\
cunt-dumpling & 4 & 2.00 & 2.75 \\
cunt-dungeon & 3 & 3.33 & 4.00 \\
cunt-funnel & 6 & 3.00 & 3.00 \\
cunt-monkey & 6 & 1.17 & 1.50 \\
cunt-puffin & 8 & 1.75 & 1.63 \\
cunt-pumpkin & 6 & 2.67 & 3.67 \\
cunt-shovel & 1 & 1.00 & 3.00 \\
cunt-shuttle & 5 & 3.00 & 3.20 \\
cunt-thnuder & 5 & 2.20 & 2.40 \\
cunt-trumpet & 7 & 3.14 & 3.57 \\
cunt-umpire & 6 & 1.83 & 2.00 \\
cunt-vulture & 8 & 3.38 & 3.63 \\
dick-biscuit & 10 & 3.30 & 3.70 \\
dick-chicken & 6 & 3.33 & 2.83 \\
dick-crystal & 5 & 2.20 & 2.20 \\
dick-cymbal & 5 & 3.00 & 3.60 \\
dick-fiddle & 4 & 2.50 & 3.00 \\
\hline & & & \\
\hline & &
\end{tabular}

\begin{tabular}{lrll}
\hline compound & $n$ & fun. & sat. \\
\hline dick-fiddler & 5 & 3.40 & 3.20 \\
dick-frisbee & 10 & 3.50 & 2.90 \\
dick-hippo & 3 & 1.00 & 1.00 \\
dick-igloo & 5 & 3.20 & 2.40 \\
dick-kipper & 6 & 2.50 & 2.67 \\
dick-pickle & 4 & 3.25 & 3.00 \\
dick-shingle & 3 & 2.67 & 3.33 \\
dick-whistle & 8 & 3.00 & 3.13 \\
fart-artist & 3 & 2.33 & 1.67 \\
fart-bargain & 8 & 2.50 & 2.38 \\
fart-carbon & 3 & 1.33 & 1.00 \\
fart-carpet & 6 & 2.17 & 1.67 \\
fart-carton & 7 & 3.29 & 3.14 \\
fart-harbor & 6 & 2.83 & 2.33 \\
fart-harvest & 8 & 2.25 & 2.50 \\
fart-marshall & 8 & 3.63 & 3.25 \\
fart-parlor & 3 & 3.00 & 2.33 \\
fart-party & 2 & 3.00 & 2.00 \\
fart-sergeant & 4 & 3.75 & 3.75 \\
fart-sharpie & 10 & 2.30 & 2.10 \\
fart-target & 7 & 3.43 & 2.57 \\
uck-bucket & 3 & 2.67 & 4.00 \\
fuck-crumble & 7 & 2.00 & 2.29 \\
fuck-dumpling & 3 & 3.00 & 4.00 \\
fuck-dungeon & 6 & 3.17 & 3.00 \\
fuck-monkey & 10 & 3.10 & 3.60 \\
fuck-puffin & 7 & 3.43 & 3.57 \\
fuck-pumpkin & 6 & 3.17 & 3.33 \\
fuck-shovel & 3 & 3.67 & 2.67 \\
fuck-shuttle & 10 & 3.20 & 3.40 \\
fuck-thunder & 7 & 3.14 & 2.57 \\
fuck-trumpet & 6 & 2.83 & 3.33 \\
fuck-umpire & 2 & 3.00 & 2.50 \\
fuck-vulture & 5 & 3.00 & 3.40 \\
piss-biscuit & 10 & 3.80 & 4.20 \\
piss-chicken & 5 & 2.40 & 2.40 \\
piss-crystal & 8 & 2.63 & 2.25 \\
piss-cymbal & 7 & 2.29 & 2.71 \\
piss-fiddle & 3 & 2.33 & 3.00 \\
piss-fidlder & 6 & 2.50 & 2.67 \\
piss-risbee & 6 & 2.67 & 2.50 \\
piss-hippo & 10 & 3.00 & 2.90 \\
\hline & & &
\end{tabular}


Matching consonants

\begin{tabular}{lrll}
\hline \multicolumn{1}{c}{ compound } & $n$ & fun. & sat. \\
\hline ass-artist & 22 & 1.82 & 1.86 \\
ass-igloo & 23 & 2.74 & 2.52 \\
ass-umpire & 30 & 2.30 & 2.13 \\
crap-carbon & 11 & 1.55 & 1.73 \\
crap-carpet & 14 & 2.14 & 1.86 \\
crap-carton & 15 & 1.60 & 1.80 \\
crap-crumble & 11 & 1.91 & 2.00 \\
crap-crystal & 10 & 1.80 & 2.00 \\
crap-kipper & 14 & 2.21 & 2.14 \\
cunt-camel & 18 & 2.56 & 2.78 \\
cunt-carbon & 14 & 1.93 & 1.93 \\
cunt-carpet & 9 & 1.89 & 2.67 \\
cunt-carton & 14 & 2.14 & 2.64 \\
cunt-crystal & 9 & 1.44 & 1.33 \\
cunt-kipper & 11 & 1.91 & 2.09 \\
dick-dragon & 28 & 3.21 & 2.82 \\
\hline
\end{tabular}

\begin{tabular}{lrll}
\hline compound & $n$ & fun. & sat. \\
\hline dick-dumpling & 26 & 2.73 & 2.73 \\
dick-dungeon & 21 & 3.10 & 3.10 \\
fart-fastner & 8 & 2.63 & 2.88 \\
fart-fiddle & 17 & 2.82 & 2.24 \\
fart-fiddler & 13 & 3.08 & 2.77 \\
fart-frisbee & 10 & 2.70 & 2.10 \\
fart-funnel & 17 & 2.59 & 2.65 \\
fart-phantom & 10 & 3.00 & 2.80 \\
fuck-farmer & 23 & 2.61 & 2.83 \\
fuck-fastner & 6 & 3.00 & 3.17 \\
fuck-fiddle & 13 & 3.00 & 3.15 \\
fuck-fiddler & 12 & 2.25 & 2.42 \\
fuck-frisbee & 9 & 2.67 & 2.44 \\
fuck-phantom & 12 & 2.00 & 2.00 \\
piss-panda & 12 & 2.92 & 3.08 \\
piss-parlor & 10 & 2.00 & 2.00 \\
\hline
\end{tabular}

\begin{tabular}{llll}
\hline compound & $n$ & fun. & sat. \\
\hline piss-party & 22 & 2.09 & 2.18 \\
piss-puffin & 16 & 3.19 & 3.13 \\
piss-pumpkin & 15 & 2.67 & 2.40 \\
shart-shadow & 11 & 2.36 & 2.18 \\
shart-shamrock & 17 & 2.24 & 2.06 \\
shart-shingle & 16 & 3.25 & 3.19 \\
shart-shovel & 17 & 2.41 & 2.59 \\
shart-shuttle & 14 & 2.43 & 2.64 \\
shit-shadow & 14 & 1.93 & 1.86 \\
shit-shamrock & 15 & 2.73 & 2.53 \\
shit-sharpie & 12 & 3.42 & 2.92 \\
shit-shovel & 13 & 2.62 & 3.23 \\
shit-shuttle & 20 & 3.05 & 3.10 \\
spunk-cymbal & 29 & 2.07 & 2.14 \\
spunk-sergeant & 22 & 2.41 & 2.36 \\
spunk-spaniel & 23 & 2.00 & 2.04 \\
\hline
\end{tabular}

Non-matching items:

\begin{tabular}{|c|c|c|c|}
\hline compound & $n$ & fun. & sat. \\
\hline ass-bargain & 1 & 1.00 & 2.00 \\
\hline ass-biscuit & 3 & 3.67 & 3.67 \\
\hline ass-bucket & 3 & 2.00 & 2.33 \\
\hline ass-carbon & 3 & 1.00 & 1.33 \\
\hline ass-carpet & 2 & 1.00 & 1.50 \\
\hline ass-carton & 2 & 1.00 & 1.00 \\
\hline ass-chicken & 1 & 2.00 & 2.00 \\
\hline ass-crumble & 2 & 2.50 & 3.00 \\
\hline ass-crystal & 1 & 3.00 & 2.00 \\
\hline ass-cymbal & 2 & 2.00 & 2.00 \\
\hline ass-dumpling & 4 & 4.00 & 2.75 \\
\hline ass-dungeon & 2 & 3.00 & 3.00 \\
\hline ass-farmer & 1 & 4.00 & 4.00 \\
\hline ass-fiddle & 1 & 4.00 & 5.00 \\
\hline ass-fiddler & 2 & 2.00 & 2.00 \\
\hline ass-frisbee & 2 & 2.00 & 1.50 \\
\hline ass-funnel & 3 & 3.33 & 3.00 \\
\hline ass-harbor & 2 & 1.00 & 1.50 \\
\hline ass-harvest & 2 & 2.00 & 1.50 \\
\hline ass-hippo & 3 & 2.00 & 1.67 \\
\hline ass-kipper & 4 & 2.00 & 2.00 \\
\hline ass-marshall & 4 & 3.25 & 3.25 \\
\hline ass-monkey & 1 & 3.00 & 2.00 \\
\hline ass-parlor & 1 & 1.00 & 1.00 \\
\hline ass-party & 1 & 2.00 & 1.00 \\
\hline ass-pickle & 1 & 3.00 & 2.00 \\
\hline ass-puffin & 1 & 3.00 & 3.00 \\
\hline ass-pumpkin & 2 & 2.50 & 3.50 \\
\hline ass-sergeant & 1 & 4.00 & 4.00 \\
\hline ass-sharpie & 1 & 4.00 & 2.00 \\
\hline ass-shingle & 1 & 2.00 & 3.00 \\
\hline ass-shovel & 3 & 3.67 & 2.67 \\
\hline ass-target & 1 & 1.00 & 1.00 \\
\hline ass-thunder & 3 & 2.33 & 2.67 \\
\hline ass-trumpet & 3 & 2.67 & 3.33 \\
\hline ass-vulture & 2 & 1.00 & 1.00 \\
\hline ass-whistle & 3 & 3.67 & 4.00 \\
\hline crap-artist & 4 & 2.75 & 3.00 \\
\hline crap-bargain & 4 & 2.50 & 2.50 \\
\hline crap-biscuit & 4 & 3.25 & 2.25 \\
\hline crap-bucket & 3 & 2.33 & 2.33 \\
\hline crap-chicken & 3 & 2.67 & 3.33 \\
\hline crap-cymbal & 2 & 1.50 & 1.50 \\
\hline crap-dumpling & 2 & 1.50 & 1.50 \\
\hline crap-dungeon & 2 & 1.00 & 1.00 \\
\hline crap-farmer & 2 & 2.50 & 2.50 \\
\hline crap-fiddle & 1 & 3.00 & 2.00 \\
\hline crap-fiddler & 3 & 3.00 & 2.33 \\
\hline crap-frisbee & 1 & 4.00 & 2.00 \\
\hline crap-harbor & 2 & 1.50 & 1.00 \\
\hline crap-hippo & 2 & 2.50 & 3.50 \\
\hline crap-marshall & 2 & 1.00 & 1.00 \\
\hline crap-monkey & 6 & 2.17 & 2.33 \\
\hline crap-parlor & 3 & 1.33 & 1.67 \\
\hline crap-party & 3 & 2.33 & 2.33 \\
\hline crap-pickle & 2 & 1.50 & 1.50 \\
\hline crap-puffin & 1 & 4.00 & 4.00 \\
\hline crap-pumpkin & 3 & 1.67 & 1.67 \\
\hline crap-sergeant & 1 & 3.00 & 3.00 \\
\hline crap-sharpie & 1 & 4.00 & 2.00 \\
\hline crap-shingle & 1 & 1.00 & 1.00 \\
\hline crap-shovel & 3 & 2.33 & 3.00 \\
\hline crap-shuttle & 4 & 1.50 & 1.75 \\
\hline crap-target & 2 & 3.00 & 2.00 \\
\hline crap-thunder & 2 & 2.00 & 1.50 \\
\hline crap-trumpet & 1 & 4.00 & 2.00 \\
\hline crap-umpire & 1 & 1.00 & 2.00 \\
\hline crap-vulture & 3 & 2.33 & 2.00 \\
\hline crap-whistle & 1 & 5.00 & 5.00 \\
\hline cunt-antler & 1 & 1.00 & 2.00 \\
\hline cunt-apple & 4 & 1.50 & 2.75 \\
\hline cunt-artist & 1 & 3.00 & 4.00 \\
\hline cunt-badger & 1 & 4.00 & 4.00 \\
\hline cunt-bargain & 3 & 1.33 & 1.67 \\
\hline cunt-biscuit & 1 & 3.00 & 4.00 \\
\hline cunt-bracket & 4 & 1.50 & 3.00 \\
\hline cunt-chicken & 7 & 2.43 & 2.86 \\
\hline cunt-cymbal & 3 & 1.67 & 1.67 \\
\hline cunt-dragon & 2 & 3.50 & 4.00 \\
\hline cunt-farmer & 1 & 2.00 & 2.00 \\
\hline
\end{tabular}

\begin{tabular}{|c|c|c|c|}
\hline compound & $n$ & fun. & sat. \\
\hline cunt-fastner & 3 & 1.33 & 1.33 \\
\hline cunt-harbor & 3 & 2.00 & 3.67 \\
\hline cunt-harvest & 1 & 2.00 & 2.00 \\
\hline cunt-hippo & 4 & 2.75 & 2.25 \\
\hline cunt-igloo & 6 & 2.50 & 2.00 \\
\hline cunt-marshall & 2 & 1.00 & 1.00 \\
\hline cunt-panda & 3 & 1.33 & 1.33 \\
\hline cunt-parlor & 2 & 2.50 & 2.50 \\
\hline cunt-party & 3 & 1.67 & 2.33 \\
\hline cunt-pickle & 1 & 2.00 & 1.00 \\
\hline cunt-rabbit & 2 & 1.50 & 2.00 \\
\hline cunt-sergeant & 3 & 2.33 & 2.33 \\
\hline cunt-shadow & 2 & 2.50 & 3.00 \\
\hline cunt-shamrock & 3 & 2.33 & 2.33 \\
\hline cunt-shingle & 4 & 2.00 & 2.00 \\
\hline cunt-target & 1 & 3.00 & 3.00 \\
\hline cunt-taxi & 3 & 3.67 & 3.00 \\
\hline cunt-whistle & 1 & 4.00 & 4.00 \\
\hline dick-antler & 4 & 3.00 & 3.00 \\
\hline dick-apple & 1 & 1.00 & 1.00 \\
\hline dick-artist & 1 & 1.00 & 1.00 \\
\hline dick-badger & 3 & 5.00 & 3.33 \\
\hline dick-bargain & 1 & 5.00 & 4.00 \\
\hline dick-bracket & 2 & 3.50 & 3.50 \\
\hline dick-bucket & 2 & 1.50 & 1.50 \\
\hline dick-camel & 5 & 1.80 & 1.60 \\
\hline dick-carbon & 1 & 4.00 & 4.00 \\
\hline dick-carpet & 1 & 4.00 & 4.00 \\
\hline dick-carton & 1 & 4.00 & 4.00 \\
\hline dick-crumble & 5 & 2.80 & 3.00 \\
\hline dick-farmer & 1 & 5.00 & 5.00 \\
\hline dick-fastner & 1 & 1.00 & 1.00 \\
\hline dick-funnel & 3 & 3.00 & 3.00 \\
\hline dick-harbor & 1 & 2.00 & 2.00 \\
\hline dick-harvest & 3 & 2.00 & 2.00 \\
\hline dick-marshall & 1 & 3.00 & 5.00 \\
\hline dick-monkey & 3 & 3.00 & 3.33 \\
\hline dick-panda & 3 & 3.00 & 2.67 \\
\hline dick-parlor & 2 & 2.50 & 2.50 \\
\hline dick-party & 2 & 4.50 & 3.00 \\
\hline dick-phantom & 1 & 3.00 & 3.00 \\
\hline dick-puffin & 4 & 2.25 & 2.50 \\
\hline dick-rabbit & 2 & 3.00 & 2.50 \\
\hline dick-sergeant & 2 & 2.00 & 2.50 \\
\hline dick-shadow & 3 & 2.00 & 2.33 \\
\hline dick-sharpie & 1 & 5.00 & 4.00 \\
\hline dick-shuttle & 1 & 2.00 & 4.00 \\
\hline dick-spaniel & 1 & 3.00 & 4.00 \\
\hline dick-target & 2 & 2.50 & 2.50 \\
\hline dick-taxi & 1 & 2.00 & 3.00 \\
\hline dick-thunder & 2 & 1.00 & 1.00 \\
\hline dick-trumpet & 5 & 3.40 & 3.80 \\
\hline dick-umpire & 1 & 2.00 & 2.00 \\
\hline dick-vulture & 2 & 2.50 & 2.50 \\
\hline fart-antler & 3 & 3.33 & 2.33 \\
\hline fart-badger & 1 & 2.00 & 2.00 \\
\hline fart-biscuit & 5 & 3.20 & 3.00 \\
\hline fart-bracket & 2 & 1.00 & 1.00 \\
\hline fart-bucket & 5 & 3.80 & 3.60 \\
\hline fart-camel & 1 & 3.00 & 3.00 \\
\hline fart-chicken & 3 & 3.00 & 2.33 \\
\hline fart-crumble & 3 & 2.67 & 2.33 \\
\hline fart-cymbal & 1 & 5.00 & 3.00 \\
\hline fart-dragon & 2 & 2.50 & 3.00 \\
\hline fart-dumpling & 1 & 4.00 & 4.00 \\
\hline fart-dungeon & 2 & 3.00 & 2.50 \\
\hline fart-hippo & 4 & 3.25 & 3.25 \\
\hline fart-kipper & 1 & 4.00 & 4.00 \\
\hline fart-monkey & 1 & 1.00 & 1.00 \\
\hline fart-panda & 2 & 4.50 & 3.00 \\
\hline fart-pickle & 3 & 4.00 & 3.33 \\
\hline fart-puffin & 3 & 4.00 & 3.33 \\
\hline fart-pumpkin & 3 & 2.33 & 2.33 \\
\hline fart-rabbit & 3 & 3.33 & 2.00 \\
\hline fart-shadow & 3 & 2.67 & 2.67 \\
\hline fart-shamrock & 3 & 4.67 & 3.00 \\
\hline $\begin{array}{l}\text { fart-shingle } \\
\text { las }\end{array}$ & 4 & 2.50 & 2.00 \\
\hline fart-shovel & 2 & 1.50 & 1.50 \\
\hline fart-shuttle & 1 & 2.00 & 3.00 \\
\hline fart-spaniel & 1 & 4.00 & 3.00 \\
\hline
\end{tabular}

\begin{tabular}{|c|c|c|c|}
\hline compound & $n$ & fun. & sat. \\
\hline shart-fiddle & 1 & 4.00 & 4.00 \\
\hline shart-frisbee & 2 & 2.00 & 2.00 \\
\hline shart-hippo & 4 & 2.50 & 2.00 \\
\hline shart-igloo & 1 & 2.00 & 2.00 \\
\hline shart-kipper & 1 & 3.00 & 3.00 \\
\hline shart-monkey & 2 & 2.00 & 3.00 \\
\hline shart-panda & 2 & 1.50 & 1.50 \\
\hline shart-phantom & 3 & 1.67 & 1.33 \\
\hline shart-pickle & 3 & 3.33 & 4.00 \\
\hline shart-pumpkin & 4 & 1.50 & 1.50 \\
\hline shart-rabbit & 4 & 2.75 & 2.50 \\
\hline shart-spaniel & 4 & 2.00 & 2.00 \\
\hline shart-taxi & 1 & 1.00 & 1.00 \\
\hline shart-thunder & 7 & 2.00 & 2.57 \\
\hline shart-trumpet & 4 & 3.25 & 2.75 \\
\hline shart-vulture & 1 & 1.00 & 1.00 \\
\hline shart-whistle & 4 & 2.00 & 2.00 \\
\hline shit-antler & 3 & 1.67 & 1.67 \\
\hline shit-apple & 3 & 1.33 & 1.33 \\
\hline shit-artist & 3 & 2.00 & 3.00 \\
\hline shit-badger & 2 & 3.00 & 3.50 \\
\hline shit-bargain & 1 & 3.00 & 1.00 \\
\hline shit-camel & 1 & 1.00 & 2.00 \\
\hline shit-carbon & 2 & 1.50 & 2.00 \\
\hline shit-carpet & 2 & 2.50 & 2.00 \\
\hline shit-carton & 2 & 2.00 & 3.00 \\
\hline shit-crumble & 3 & 2.00 & 2.00 \\
\hline shit-dumpling & 1 & 3.00 & 2.00 \\
\hline shit-dungeon & 1 & 1.00 & 1.00 \\
\hline shit-farmer & 3 & 3.00 & 2.67 \\
\hline shit-fastner & 5 & 2.40 & 2.60 \\
\hline shit-funnel & 1 & 2.00 & 2.00 \\
\hline shit-harbor & 2 & 3.00 & 3.00 \\
\hline shit-harvest & 4 & 3.50 & 3.50 \\
\hline shit-marshall & 3 & 2.33 & 2.33 \\
\hline shit-monkey & 3 & 3.00 & 4.00 \\
\hline shit-panda & 1 & 1.00 & 1.00 \\
\hline shit-parlor & 4 & 3.00 & 3.25 \\
\hline shit-phantom & 4 & 3.25 & 2.75 \\
\hline shit-pumpkin & 1 & 1.00 & 1.00 \\
\hline shit-rabbit & 3 & 2.33 & 2.67 \\
\hline shit-sergeant & 2 & 3.00 & 3.50 \\
\hline shit-spaniel & 3 & 2.00 & 2.67 \\
\hline shit-taxi & 2 & 2.50 & 3.00 \\
\hline shit-thunder & 4 & 1.75 & 1.75 \\
\hline shit-umpire & 4 & 1.50 & 1.50 \\
\hline shit-vulture & 2 & 2.50 & 3.50 \\
\hline spunk-antler & 3 & 2.33 & 2.67 \\
\hline spunk-badger & 1 & 4.00 & 2.00 \\
\hline spunk-bargain & 2 & 2.00 & 2.50 \\
\hline spunk-biscuit & 2 & 2.50 & 2.50 \\
\hline spunk-bracket & 1 & 3.00 & 3.00 \\
\hline spunk-camel & 2 & 2.50 & 3.00 \\
\hline spunk-carbon & 2 & 1.00 & 1.00 \\
\hline spunk-carpet & 4 & 1.75 & 2.00 \\
\hline spunk-carton & 5 & 2.60 & 2.80 \\
\hline spunk-chicken & 2 & 1.50 & 1.50 \\
\hline spunk-crystal & 2 & 1.50 & 2.00 \\
\hline spunk-dragon & 2 & 3.50 & 2.00 \\
\hline spunk-farmer & 2 & 3.50 & 3.50 \\
\hline spunk-fastner & 4 & 1.75 & 2.00 \\
\hline spunk-fiddle & 2 & 2.50 & 3.00 \\
\hline spunk-fiddler & 1 & 4.00 & 3.00 \\
\hline spunk-frisbee & 2 & 2.50 & 2.50 \\
\hline spunk-harbor & 2 & 2.50 & 2.00 \\
\hline spunk-harvest & 2 & 1.00 & 2.50 \\
\hline spunk-hippo & 5 & 2.40 & 1.40 \\
\hline spunk-marshall & 2 & 2.50 & 3.00 \\
\hline spunk-panda & 2 & 1.50 & 2.00 \\
\hline spunk-parlor & 2 & 1.50 & 1.50 \\
\hline spunk-party & 3 & 1.67 & 1.67 \\
\hline spunk-pickle & 4 & 3.50 & 2.50 \\
\hline spunk-rabbit & 1 & 1.00 & 1.00 \\
\hline spunk-sharpie & 2 & 1.50 & 1.50 \\
\hline spunk-shingle & 3 & 2.33 & 1.33 \\
\hline spunk-target & 3 & 1.00 & 1.00 \\
\hline spunk-taxi & 3 & 2.00 & 1.67 \\
\hline spunk-whistle & 2 & 2.50 & 3.50 \\
\hline
\end{tabular}




\section{References}

Bates, Douglas, Martin Mächler, Ben Bolker \& Steve Walker (2015). Fitting linear mixed-effects models using lme4. Journal of Statistical Software 67:1, 1-48.

Becker, Michael \& Jonathan Levine (2015). Experigen - an online experiment platform. Available at https://github.com/tlozoot/experigen.

Berent, Iris, Colin Wilson, Gary Marcus \& Doug Bemis (2012). On the role of variables in phonology: Remarks on Hayes and Wilson 2008. Linguistic Inquiry 43, 97-119.

Boyd-Bowman, Peter (1955). Cómo obra la fonética infantil en la formación de los hipocorísticos. Nueva Revista de Filología Hispánica 9:337-366.

Elfner, Emily \& Wendell Kimper (2008). Reduplication without red: Evidence from diddly-infixation. Abner, Natasha \& Jason Bishop (eds.), Proceedings of the 27th West Coast Conference on Formal Linguistics, Cascadilla Press.

Gallagher, Gillian (2010). Perceptual distinctness and long-distance laryngeal restrictions. Phonology 27:3, 435-480.

Gallagher, Gillian (2013). Learning the identity effect as an artificial language. Phonology 30:2, 253-295.

Goldrick, Matthew (2002). Patterns of sound, patterns in mind: Phonological regularities in speech production. Ph.D. thesis, Johns Hopkins University.

Goldwater, Sharon \& Mark Johnson (2003). Learning OT constraint rankings using a maximum entropy model. Spenader, Jennifer, Anders Eriksson \& Osten Dahl (eds.), Proceedings of the Stockholm Workshop on Variation within Optimality Theory, 111-120.

Heinz, Jeffrey (2010). Learning long-distance phonotactics. Linguistic Inquiry 41:4, 623-661.

Jones, Taylor (2017). URL http://www.languagejones.com/blog-1/2017/2/9/linguists-havebeen-discussing-shit-gibbon-i-argue-its-not-entirely-about-gibbons.

Kennedy, Robert \& Tania S. Zamuner (2006). Nicknames and the lexicon of sports. American Speech 81:4.

Levin, Beth, Lelia Glass \& Dan Jurafsky (to appear). Systematicity in the semantics of noun compounds: The role of artifacts vs. natural kinds.

Linzen, Tal \& Gillian Gallagher (2017). Rapid generalization in phonotactic learning. Laboratory Phonology: Journal of the Association for Laboratory Phonology 8(1):24, 1-32.

MacEachern, Margaret R (1999). Laryngeal Cooccurrence Restrictions. Garland, New York.

Martin, Andrew (2007). The evolving lexicon. Ph.D. thesis, UCLA.

McCarthy, John J. (1979). Formal Problems in Semitic Phonology and Morphology. Ph.D. thesis, MIT.

McCarthy, John J. (1982). Prosodic structure and expletive infixation. Language 58:3, 574-590.

McCarthy, John J. \& Alan Prince (1998). Prosodic morphology. Spencer, Andrew \& Arnold Zwicky (eds.), The Handbook of Morphology, Basil Blackwell, 283-305.

McMullin, Kevin (2016). Tier-based locality in long-distance phonotactics: learnability and typology. Ph.D. thesis, University of British Columbia.

Moreton, Elliott, Jennifer L. Smith, Katya Pertsova, Rachel Broad \& Brandon Prickett (2017). Emergent positional privilege in novel english blends. Language 93:2, 347-380.

Pearce, Mary (2003). Vowel Harmony in Kera [Chadic]. Master's thesis, University College London.

R Core Team (2016). R: A language and environment for statistical computing. Vienna, Austria. (http://www.rproject.org).

Rose, Sharon \& Rachel Walker (2011). Harmony systems. Goldsmith, John, Jason Riggle \& Alan Yu (eds.), The Handbook of Phonological Theory, Second Edition, Wiley-Blackwell, 240-290.

Ryan, Kevin (submitted). Prosodic end-weight reflects phrasal stress. Ms. Harvard.

Sepp, Mary (2006). Phonological constraints and free variation in compounding: A Corpus Study of English and Estonian Noun Compounds. Ph.D. thesis, CUNY.

Shattuck-Hufnagel, Stefanie (1979). Speech errors as evidence for a serial-ordering mechanism in sentence production. Cooper, W. E. \& E. C. T. Walker (eds.), Sentence processing: psycholinguistc studies presented to Merrill Garrett, Lawrence Erlbaum, 295-342.

Smolensky, Paul \& Géraldine Legendre (2006). The Harmonic Mind: From Neural Computation To Optimality-Theoretic Grammar. MIT Press.

Viau, Joshua (2006). Introducing English [iz]-infixation: Snoop Dogg and bey[iz]ond. Paper presented at the LSA Summer Meeting, East Lansing, MI.

Wedel, Andrew B. (2007). Feedback and regularity in the lexicon. Phonology 24, 147-185.

Yu, Alan (2003). Reduplication in English Homeric infixation. Moulton, Keir \& Matthew Wolf (eds.), Proceedings of the 34th North East Linguistic Society, GLSA, vol. 34, 619-633.

Zimmer, Ben (2017). URL http://www.slate.com/blogs/browbeat/2017/02/13/the_origin_of -the_trump_insult_shitgibbon_revealed.html. 